\title{
Transgenically Enhanced Expression of Indole-3-Acetic Acid Confers Hypervirulence to Plant Pathogens
}

\author{
Barry A. Cohen, Ziva Amsellem, Rudy Maor, Amir Sharon, and Jonathan Gressel
}

First, second, and fifth authors: Department of Plant Sciences, Weizmann Institute of Science, Rehovot IL-76100, Israel; and third and fourth authors: Department of Plant Sciences, Tel Aviv University, IL-69978 Tel Aviv, Israel.

Accepted for publication 14 January 2002.

\begin{abstract}
Cohen, B. A., Amsellem, Z., Maor, R., Sharon, A., and Gressel, J. 2002. Transgenically enhanced expression of indole-3-acetic acid confers hypervirulence to plant pathogens. Phytopathology 92:590-596.

Fusarium oxysporum and $F$. arthrosporioides, pathogenic on Orobanche aegyptiaca, were transformed with two genes of the indole-3acetamide (IAM) pathway leading to indole-3-acetic acid (IAA) to attempt to enhance virulence. Transgenic $F$. oxysporum lines containing both the tryptophan-2-monooxyngenase (iaaM) and indole-3-acetamide hydrolase $(i a a H)$ genes produced significantly more IAA than the wild type. IAM accumulated in culture extracts of $F$. oxysporum containing iaaM alone. F. arthrosporioides containing only iaaM accumulated IAM

and an unidentified indole. Some transformants of $F$. oxysporum expressing only the $i a a M$ gene also produced more IAA than the wild type. Sub-threshold levels (that barely infect Orobanche) of transgenic $F$. oxysporum expressing both genes and of $F$. arthrosporioides expressing iaaM were more effective in suppressing the number and size of Orobanche shoots than the wild type on tomato plants grown in soil mixed with Orobanche seed. Stimulating an auxin imbalance enhanced pathogen virulence by affecting the host in a manner similar to low doses of auxin herbicides such as 2,4-dichlorophenoxy acetic acid.

Additional keywords: formulation, polymerase chain reaction, transformation.
\end{abstract}

The Orobanche spp. (broomrapes) are obligate flowering parasites attacking cultivated plants causing severe damage (23). Two fungal pathogens of Orobanche, Fusarium oxysporum and $F$. arthrosporioides, were isolated from young diseased shoots and have been studied to evaluate their mycoherbicidal potential for the control of Orobanche $(1,2)$. Methods were developed to preserve the mycelia of $F$. oxysporum and $F$. arthrosporioides in the formulant Stabileze that allowed storage for more than a year with rapid infection of Orobanche upon rehydration (1). Formulated $F$. oxysporum and $F$. arthrosporioides reduce the occurrence of $O$. aegyptiaca tubercles by 50 to $100 \%$ at very high inoculation levels on in vitro and greenhouse-cultivated tomato plants $(1,2)$. Strategies are needed to improve the mycoherbicidal organisms so this potential can lead to effective, consistent, field use at lower inoculum levels. One strategy to improve the capability of the fungi to kill Orobanche spp. is by transgenically enhancing virulence.

The auxins (i.e., indole-3-acetic acid [IAA]) control plant growth, differentiation, structural organization, and the shift from vegetative to reproductive growth (15). Exogenous IAA can lead to cellulase-catalyzed cleavage of hemicellulose (13), resulting in wall loosening $(33,36)$ and membrane leakage, thereby stimulating the loss of water and nutrients (4,5). Synthetic auxins such as 2,4-dichlorophenoxy acetic acid (2,4-D) affecting the same receptors are fully herbicidal (9). Many microorganisms associated with plants as symbionts or parasites directly alter the auxin content of the host; the auxin imbalance benefits the microorganisms $(15,34)$. The apices of Euphorbia cyparissias infected by Uromyces pisi contained 10 times more auxin than the level found in healthy apices (17). Pathogen strain virulence directly correlated with the levels of IAA, suggesting that IAA has a positive function in the infection process (11). Plants preinfected with a patho-

Corresponding author: J. Gressel; E-mail address: jonathan.gressel@weizmann.ac.il

Publication no. P-2002-0415-01R

(C) 2002 The American Phytopathological Society gen caused auxin production, which then overcame the hypersensitive defense response of plants subsequently infected by an incompatible pathogen (26). Chitinase production by plant tissues as a defense against pathogens was blocked by auxin, enhancing the virulence of the pathogens (30). Bacterial pathogens causing crown and root gall diseases all produce IAA, and mutants deficient in IAA production are not tumorogenic (31). Full virulence was restored when these mutants were transformed with genes for IAA synthesis (7). Pathogenic strains of Erwinia herbicola use the indole-3-acetamide (IAM) pathway for the production of IAA, whereas nonpathogenic strains were devoid of this pathway (22). The IAM pathway (Fig. 1) is uncommon in plants, with some possible exceptions $(18,19,25,29)$. Bacterial pathogens having the IAM pathway may override the regulation of IAA production by the host by using precursors from the host or synthesized by the pathogen (22).

We tested the hypothesis that increased production of IAA may confer hypervirulence to Fusarium on Orobanche. To the best of our knowledge, this is the first publication demonstrating that by transgenically enhancing IAA levels, virulence is further increased. In this case, enhancing IAA production by Fusarium spp. reduced the severity of Orobanche infestation on the host plants by increasing fungal virulence.

\section{MATERIALS AND METHODS}

Fungal strains. F. oxysporum Schlechtend.:Fr. and F. arthrosporioides Sherb. were isolated as single spore colonies from diseased, juvenile, emerging O. aegyptiaca Pers. flower stalks from a melon field in northern Israel (2). The fungi were deposited at the Collection Nationale de Cultures de Microorganisms at the Institut Pasteur under accession numbers I-1622 (F. oxysporum) and I-1621 (F. arthrosporioides). Both fungal strains met Koch's postulates for primary pathogens.

Fungal growth media. All of the fungal strains were maintained on potato glucose agar (PDA) or potato glucose broth (PDB) (Oxoid, Basingstoke, England). 
Protoplast isolation. Fungal protoplasts were axenically isolated. Both $F$. oxysporum and $F$. arthrosporioides were cultured on PDA containing $50 \mu \mathrm{g}$ of chloramphenicol per $\mathrm{ml}$ in petri plates and incubated at $25^{\circ} \mathrm{C}$ under fluorescent lighting for a 12-h photoperiod. Washed spores of $F$. oxysporum and $F$. arthrosporioides from 2-week-old cultures were filtered through 74- $\mu \mathrm{m}$ mesh Nytex nylon monofilament screens (Swiss Bolting Cloth, Zurich, Switzerland) to remove mycelia, sedimented, and adjusted to a spore density of $10^{6}$ per $\mathrm{ml}$ in the above medium. The spore suspensions were germinated on a shaker for 20 to $22 \mathrm{~h}$ until small mycelial clumps were formed. The mycelial suspensions retained on $74-\mu \mathrm{m}$ mesh screens were transferred to digestion medium: sterile filtered $0.7 \mathrm{M} \mathrm{NaCl}, 10 \mathrm{mg}$ of glucanase per ml, $10 \mathrm{mg}$ of Fluka Driselase (ex Basidiomycetes spp.), and $50 \mu \mathrm{g}$ of Sigma chitinase per $\mathrm{ml}$ (ex Streptomyces griseus). Flasks with $5 \mathrm{~g}$ of mycelia and $25 \mathrm{ml}$ of digestion medium were incubated at $30^{\circ} \mathrm{C}$ for 1.5 to $2.5 \mathrm{~h}$ at $70 \mathrm{rpm}$. The protoplasts released were separated from mycelia and cell debris by filtration through a 74- $\mu \mathrm{m}$ mesh screen, which passed the protoplasts and retained the undigested material. The protoplasts were centrifuged at $1500 \times g$ for $5 \mathrm{~min}$, and the pellet was resuspended in $10 \mathrm{ml}$ of unbuffered $0.7 \mathrm{M} \mathrm{NaCl}$ and recentrifuged. The protoplast pellet was then washed in $10 \mathrm{ml}$ of sterile STC (1.2 M sorbitol, $10 \mathrm{mM}$ Tris-HCl, pH 7.5, and $50 \mathrm{mM}$ $\mathrm{CaCl}_{2}$ ). Aliquots of protoplasts were counted in a hemacytometer cell and adjusted to a density of $10^{8}$ protoplasts per $\mathrm{ml}$ of STC.

Plasmids. The tryptophan-2-monooxyngenase (iaaM) gene (1,663 bp) was amplified by polymerase chain reaction (PCR) from the vector pCP3 (37) and cloned into the SacI and KpnI sites of pWCG2 (27). Next, a XbaI/EcoRV fragment containing the Aspergillus nidulans trpC promoter was introduced at the SmaI/XbaI site upstream of the iaaM gene. The resulting plasmid pWCG2pM $(8,261 \mathrm{bp})$ contains the hygromycin B phosphotransferase resistance (hph) gene driven by the Cochiobolus heterostrophus $\mathrm{P} 1$ promoter and the iaaM gene driven by the A. nidulans trpC promoter.

The indole-3-acetamide hydrolase $(\mathrm{iaaH})$ gene $(1,385 \mathrm{bp})$ was amplified by PCR from the vector pCP3 and cloned into the NcoI and HindIII sites of pAN52-1 plasmid between the gdph promoter and the trpC terminator (24). The resulting plasmid was cut with $B g l I I$ and HindIII and the fragment containing the gpdh-iaaH-trpC cassette was ligated into the BamHI/HindIII sites of pC8HS. The resulting plasmid pWh52-1 contains the P1-hph cassette and the $i a a H$ gene driven by $A$. nidulans gpdh promoter and terminated with the $A$. nidulans $\operatorname{trp} C$ terminator.

Transformation. The transformations of the Fusarium spp. were based on the method of Turgeon et al. (35) using fungal protoplasts with polyethylene glycol (PEG) and $\mathrm{CaCl}_{2}$ to mediate the transformation. Protoplasts $\left(10^{7}\right.$ in $100 \mu \mathrm{l}$ of STC) were incubated at $4{ }^{\circ} \mathrm{C}$ with $25 \mu \mathrm{g}$ of plasmid DNA for single transformations or $12.5 \mu \mathrm{g}$ of DNA each in the cotransformations. The tubes were gently rolled and tilted back and forth for $5 \mathrm{~min}$ at $4{ }^{\circ} \mathrm{C}$. Sterile PEG/ $\mathrm{CaCl}_{2}$ medium (60\%, wt/vol, PEG molecular weight 3,500 to 4,000 in $10 \mathrm{mM}$ Tris- $\mathrm{HCl}, \mathrm{pH} \mathrm{7.5}$, and $50 \mathrm{mM} \mathrm{CaCl}$ ) was added in three aliquots $(200,200$, and $800 \mu \mathrm{l})$ at 5-min intervals. The protoplasts were incubated on ice for an additional $20 \mathrm{~min}$ and diluted with $1 \mathrm{ml}$ of STC medium to reach a calculated density of $4.35 \times 10^{6}$ protoplasts per $\mathrm{ml}$.

Preliminary dose response curves demonstrated that $F$. oxysporum and $F$. arthrosporioides wild-type fungal cultures were totally inhibited by 65 and $25 \mu \mathrm{g}$ of hygromycin per $\mathrm{ml}$ of medium, respectively (6). Aliquots $(200 \mu \mathrm{l})$ of putatively transformed protoplasts were mixed into $20 \mathrm{ml}$ of molten $\left(45^{\circ} \mathrm{C}\right)$ sterilized regeneration medium (PDB with $20 \%$ sucrose, $1.6 \%$ Difco agar, and $50 \mu \mathrm{g}$ of chloramphenicol per $\mathrm{ml})$. Three hours later, each plate was overlaid with $10 \mathrm{ml}$ of $\left(45^{\circ} \mathrm{C}\right)$ molten regeneration medium containing three times more hygromycin than totally inhibited growth of the nontransformed cultures. The sealed petri plates were incubated at $28^{\circ} \mathrm{C}$, and hygromycin-resistant colonies became visible on the selection plates after 3 to 7 days.

The putative transformants were picked, subcultured onto slants with PDA with 65 or $25 \mu \mathrm{g}$ of hygromycin per $\mathrm{ml}$ for $F$. oxysporum and $F$. arthrosporioides, respectively, and kept at $4^{\circ} \mathrm{C}$ after growth reached $7-\mathrm{cm}$ in diameter. The cultures were subcultured on hygromycin-containing medium at least six times and remained stable for more than 1 year.

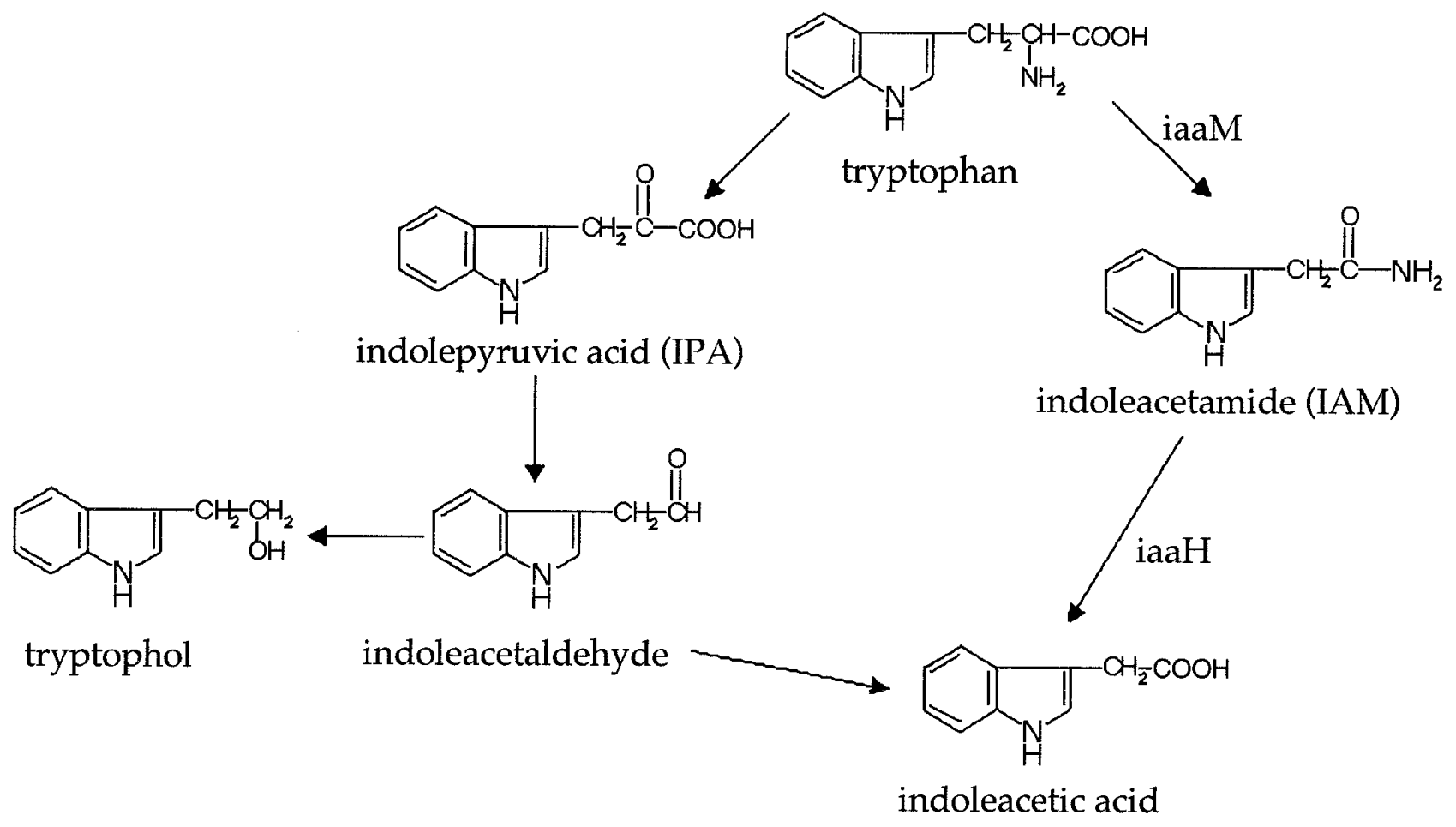

Fig. 1. The biosynthesis pathways leading to indole-3-acetic acid (IAA). Either or both the indole-3-acetamide (IAM) (21) and the indole-3-pyruvate acid (IPA) (32) biosynthesis pathways of IAA are found in different microorganisms. The IPA pathway is considered the major IAA synthesis pathway in plants. Source modified from Magie et al. (21). 
Detection of IAA and related indoles. Methods for the culturing of the fungi and the extraction and detection of IAA from the culture medium were based on Robinson et al. (27), as adapted for $F$. oxysporum and $F$. arthrosporioides. Mycelia were cultured in PDB supplemented with $5 \mathrm{mM}$ filter-sterilized Ltryptophan (in foil-covered flasks to prevent indole photodegradation) until the fungal growth reached stationary phase. The hyphae were separated from the medium by centrifugation, and the supernatant was brought to $\mathrm{pH} 3.0$ with $\mathrm{HCl}$ and mixed with an equal volume of ethyl acetate. The medium and ethyl acetate were vortex mixed at the top speed for $45 \mathrm{~s}$ and placed at $-20^{\circ} \mathrm{C}$ overnight to freeze the aqueous phase and form ice crystals around impurities at the interface. The ethyl acetate upper phase was rapidly poured through Miracloth to remove ice crystals. The ethyl acetate was evaporated in vacuo and the dried residues were resuspended in $500 \mu \mathrm{l}$ of methanol containing $1 \%$ butylated hydroxytoluene to prevent auto-oxidation of indoles.

Thirty-microliter aliquots of each of the samples were loaded onto separate lanes on a $20 \times 20 \mathrm{~cm} \times 0.25 \mathrm{~mm}$ precoated silica gel $60 \mathrm{~F}_{254}$ thin-layer chromatographic (TLC) glass plates (Merck, Darmstadt, Germany). Standards $(2.5 \mu \mathrm{l}$ of $10 \mathrm{mM}$ IAA, IAM, or tryptophol) were loaded in separate lanes on the TLC plates. The indoles were separated by chloroform/methanol/water $(84: 14: 1)$ for approximately $45 \mathrm{~min}$. Indoles were detected on the air-dried plates by spraying until they appeared transparent with Ehmann's reagent (10) containing $0.5 \% \quad(\mathrm{wt} / \mathrm{vol}) \quad p$-dimethylaminobenzaldehyde, $1.5 \mathrm{M} \mathrm{HCl}, 12.5 \%$ ethanol, $7.1 \mathrm{mM} \mathrm{FeCl}_{3}$, and $7.8 \mathrm{M}$ $\mathrm{H}_{2} \mathrm{SO}_{4}$. The dark blue staining of the indoles was intensified by heating at $100^{\circ} \mathrm{C}$ for $10 \mathrm{~min}$. Hydrochloric acid (which causes yellowing) was removed by submerging the plates in water for approximately $15 \mathrm{~min}$. The air-dried plates were scanned, and images were saved in Adobe Photoshop. The various indoles in the samples were compared with the $R_{f}$ values of the indole standards.

Quantification of IAA. The indoles were viewed as quenched spots on unsprayed TLC plates in $254 \mathrm{~nm}$ UV light. Marked spots of separated IAA, reference standards, and silica blanks were separately scraped into tubes. One milliliter of absolute ethanol was added to each tube to dissolve IAA from the silica by vortex mixing at the medium setting for $1 \mathrm{~min}$. The supernatants were removed and centrifuged twice. The absorbance of supernatants was measured at $225 \mathrm{~nm}$ against blanks. The absorbance of each of the samples was recorded and converted to nanograms of IAA based on a series of standards.
PCR analysis of gene introgression in chromosomal DNA. PCR was used to amplify iaaM and iaaH gene fragments in the genomic DNA of putatively transformed $F$. oxysporum and $F$. arthrosporioides strains to assay for integration into the fungal genome. Genomic DNA was extracted from mycelia according to Daboussi et al. (8). The unique primer pairs chosen from the iaaM and $i a a H$ gene sequences were 5'-CGGGTAGGTCGCATTTCCAGA and 5'-CGTCGGGTGTATCGCAGCAAC (iaaM) and 5'-GGATGGCGAGGTGGAGA and 5'-CCCGACAGGAATAGTAATGGA $(\mathrm{iaaH})$. The primers were prepared by the Oligonucleotide and Peptide Sequence Unit at the Weizmann Institute. The optimal annealing temperatures for the primers were determined using the Oligo primer analysis version 5.1 computer software program: $58^{\circ} \mathrm{C}$ for $i a a M$ and $56^{\circ} \mathrm{C}$ for $i a a H$ genes, respectively. Both PCR programs had the double-stranded DNA denaturation at $94^{\circ} \mathrm{C}$ for $1 \mathrm{~min}$, primer extension at $72^{\circ} \mathrm{C}$ for $1 \mathrm{~min}$, and annealing for $1 \mathrm{~min}$ for 30 cycles of denaturation, annealing, and extension in a Peltier Cycler (PTC-200; MJ Research, Watertown, MA) PCR apparatus. PCR products were analyzed by gel electrophoresis and ethidium bromide staining.

TABLE 1. Production of indole-3-acetic acid (IAA) by various transformants $^{\mathrm{a}}$

\begin{tabular}{|c|c|c|c|c|c|}
\hline \multirow[b]{2}{*}{ Strain } & \multirow[b]{2}{*}{ Strain no. } & \multicolumn{2}{|c|}{ PCR } & \multicolumn{2}{|c|}{$\mathrm{ng}$ of IAA/mg of myc } \\
\hline & & iaaM & $i a a H$ & - try & +try \\
\hline \multicolumn{6}{|c|}{ Fusarium oxysporum } \\
\hline Nontransformed & Wild type & - & - & 3 & 16 \\
\hline iaaM, iaaH & 42 & + & + & 6 & 62 \\
\hline$i a a M, i a a H$ & 76 & + & + & 4 & 190 \\
\hline$i a a M, i a a H$ & 82 & + & + & 15 & 91 \\
\hline iaaM & 47 & + & - & 7 & 17 \\
\hline iaaM & 62 & + & - & 6 & 33 \\
\hline \multicolumn{6}{|l|}{ F. arthrosporioides } \\
\hline Nontransformed & Wild type & - & - & 9 & 12 \\
\hline iaaM & 5 & + & - & 9 & 20 \\
\hline iaaM & 14 & + & - & 8 & 26 \\
\hline iaaM & 20 & + & - & 11 & 24 \\
\hline
\end{tabular}

a Polymerase chain reaction (PCR) analysis was performed on genomic DNA of the putative transformants to confirm the presence of the iaaM and iaaH transcripts. Expected positive confirmation was marked + , negative results were marked -. Differences in IAA production between all strains of $($ iaaM+iaaH)F. oxysporum versus wild type. F. oxysporum were significant at $P<0.05$ as determined by Student's paired $t$ test $($ myc $=$ mycelium; + try $=5 \mathrm{mM}$ tryptophan added to the culture medium). primed for iaaM

(43s fragment)

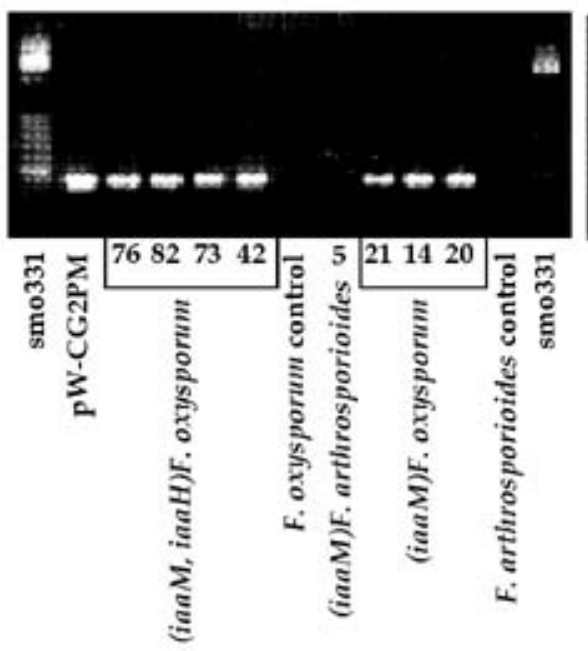

primed for ianH

(491 fragment)

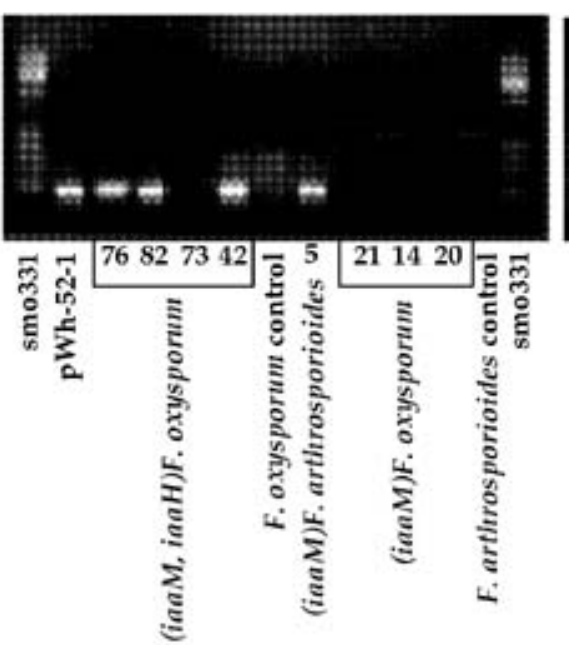

primed for iaaM

(438 fragment)

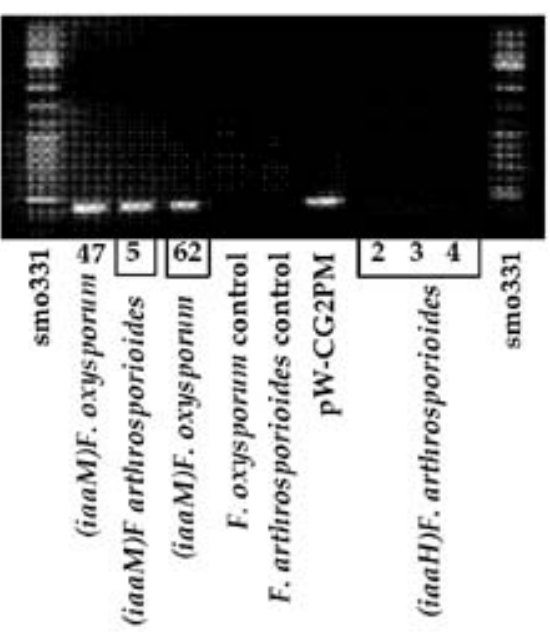

Fig. 2. Presence of polymerase chain reaction products of iaaM and iaaH in various Fusarium oxysporum and F. arthrosporioides transformants. 
The gels were prepared as $1.5 \%$ agarose in Tris-acetate-EDTA (TEA) buffer, and a 1-kb DNA ladder (GeneRuler smo331; MBI Fermentas, Hanover, MD) was used as the size markers.

Formulation. Fungi were cultured in $500 \mathrm{ml}$ of PDB in Erlenmeyer flasks aerated at $150 \mathrm{rpm}$ at $25^{\circ} \mathrm{C}$. The fungi in late exponential phase of growth were harvested onto Miracloth in vacuo after $48 \mathrm{~h}$. The retained mycelia were washed with $200 \mathrm{ml}$ of glass-distilled water to remove the culture medium. The mycelia were fragmented in a blender and formulated in Stabileze according to Amsellem et al. (3).

Soil mixture. The soil consisted of unsterilized loam containing $15 \%$ peat and $6 \mathrm{~g} / \mathrm{kg}$ of fertilizer 19-6-11 (Multicote 4 Extra Control Release; Agrimport Haifa Chem. Ltd., Haifa).

Plant material. Seeds of O. aegyptiaca (Pers.) (Egyptian broomrape) were provided by the lab of Y. Kleifeld of the Newe Yaar Research Center, Ramat Ishay, Israel. Seeds were surface sterilized in hypochlorite as previously outlined (2) and mixed into the soil $(15 \mathrm{mg} / \mathrm{kg}$ of soil $=\approx 5,000$ seeds per $\mathrm{kg}$ of soil $)$.

Tomato (Lycopersicon esculentum Mill. cv. M82) seedlings with two to three expanded leaves in speedling insert trays were provided by Hishtil Inc., Ashkelon, Israel. The tomato plants were grown at $25^{\circ} \mathrm{C}$ under $70 \mu \mathrm{Ein} / \mathrm{m}^{2} / \mathrm{s}$ fluorescent light with a $14-\mathrm{h}$ photoperiod.

Fungal virulence. The virulence of the transgenic fungi versus the wild-type $F$. oxysporum and $F$. arthrosporioides was tested in two experiments. The formulated mycelia were mixed into the soil at inoculum loadings of 80,400 , and 2,000 CFU/g of soil (first experiment) and 2,000 and 3,000 CFU/g of soil (second experiment). The inoculum loadings of the wild type were previously demonstrated as being under the threshold for reproducible infection (6). The formulated mycelia were mixed into the soil and placed separately in 3-liter plastic pots. All inoculant treatments were replicated in three pots in the first experiment and five pots in the second experiment, and the pots were randomized in the greenhouse with 16 -h light at $27 \pm 3^{\circ} \mathrm{C}$. Each pot initially contained a tomato seedling with three expanded leaves. Both the number and the size of the Orobanche shoots that emerged in pots were evaluated weekly when Orobanche shoots began to emerge. The experiments were terminated when Orobanche began flowering, at about 10 weeks after transplanting, to prevent Orobanche seed production due to biosafety considerations.
Statistical analysis. The data were analyzed using Student's paired $t$ test.

\section{RESULTS}

Verification of transformation. Plasmid DNA preparations containing the $i a a M$ or the $i a a H$ genes were used separately to transfer single plasmid DNA or several together to cotransform into $F$. oxysporum and $F$. arthrosporioides. Each plasmid carried the $(h p h)$ gene as a selectable marker. The presence of the indole biosynthesis genes was confirmed by PCR amplification of gene fragments of $i a a M$ and $i a a H$ in the genomic DNA of various putative transformants (Fig. 2; Table 1). The presence of either iaaM, iaaH in single transformants, or both genes in the cotransformants was positively confirmed, except iaaH was not confirmed in strain 73, which was a putative cotransformant (Fig. 2; Table 1).

Overproduction of indoles: IAM. Transformants were cultivated in a medium with tryptophan so that the substrate for IAA production would not be limiting. Culture extracts were TLC fractionated together with indole standards. IAM was not detected in untransformed $F$. oxysporum but it accumulated in the culture extracts of many of the (iaaM)F. oxysporum transformants (Fig. 3A). IAM accumulated in both the culture medium of (iaaM)F. arthrosporioides strains and in the wild-type $F$. arthrosporioides (Fig. 3C). An unidentified indole $\left(R_{f}=0.63\right)$ was detected in culture medium of some (iaaM)F. arthrosporioides strains that was not detected in the filtrate of wild-type $F$. arthrosporioides (Fig. 3C).

Overproduction of indoles: IAA. Some of the $(i a a M+i a a H) F$. oxysporum cotransformants had greatly increased production and excretion of IAA, especially transformants 76, 82, and 86 (Fig. 3B). The $i a a H$ gene product in transformants of $(i a a M+i a a H) F$. oxysporum presumably hydrolyzed the IAM to IAA. Some strains of single transformants of (iaaM)F. oxysporum and (iaaM)F. arthrosporioides excreted slightly more IAA in the culture medium than the amounts produced by wild-type $F$. oxysporum and $F$. arthrosporioides (Fig. 3A and C). The transformants were cultivated in a medium with and without a supplement of $5 \mathrm{mM} \mathrm{L-}$ tryptophan to ascertain if the precursor might be limiting in culture. IAA was quantified by spectrophotometry (Table 1). Both

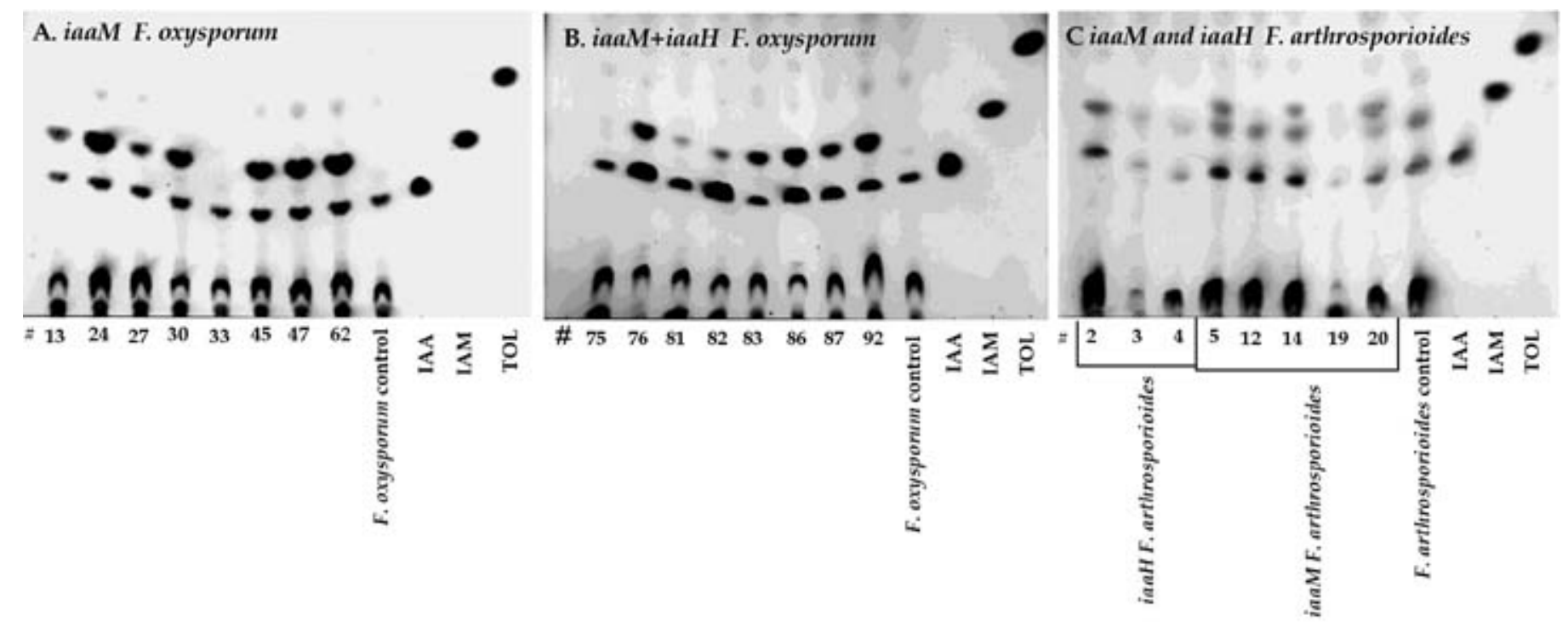

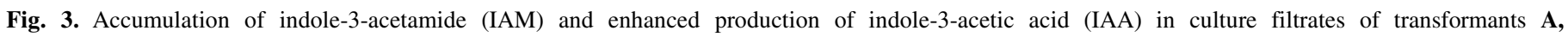

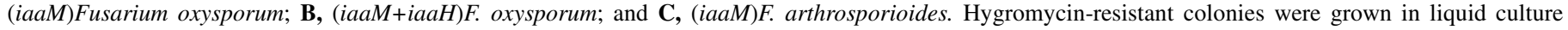

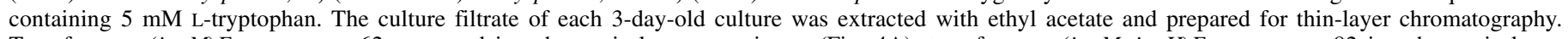

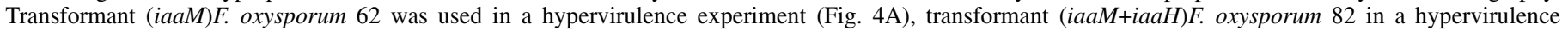
experiment (Fig. 4B), and transformant (iaaM)F. arthrosporioides 5 was used in both hypervirulence experiments (Fig. 4A and B). 
transgenic and wild-type $F$. oxysporum and $F$. arthrosporioides strains produced less than $16 \mathrm{ng}$ of IAA per mg fresh weight of mycelium on medium not supplemented with L-tryptophan. Transgenic $F$. oxysporum strains containing iaaM but lacking the $i a a H$ gene produced up to $78 \mathrm{ng}$ of IAA per mg of mycelium grown in the presence of L-tryptophan. However, transgenic $F$. oxysporum strains having both the iaaM and $i a a H$ produced twice as much IAA as the best $F$. oxysporum strain containing only the iaaM gene on L-tryptophan medium. Transgenic F. arthrosporioides having either the $i a a M$ or $i a a H$ gene produced up to $31 \mathrm{ng}$ of IAA per $\mathrm{mg}$ of mycelium when supplemented with L-tryptophan. Strains of $($ iaaM+iaaH)F. oxysporum 42, 76, and 82 overproduced IAA in several different experiments (Table 1). Some transgenic $F$. arthrosporioides cultures having the iaaM gene produced more IAA than wild-type $F$. arthrosporioides grown in the presence of L-tryptophan (data not shown).

Production of tryptophol. Tryptophol is an alternative product of the indole-3-pyruvate acid (IPA) pathway (Fig. 1). The detection of tryptophol in the fractionated samples would imply that the fungi could also use the IPA pathway of IAA synthesis (27). A minor tryptophol TLC spot was seen in TLC separations of all of the $F$. oxysporum and $F$. arthrosporioides culture extracts (Fig. $3 \mathrm{~A}, \mathrm{~B}$, and $\mathrm{C}$ ). It can be surmised that the IPA pathway may be active in these fungal species.
Hypervirulence of transformed strains. The virulence of selected strains of the transgenic fungi on Orobanche was tested in two experiments. Tomato plants were grown in soil mixed with Orobanche seeds and wild type or selected transgenic $F$. oxysporum and $F$. arthrosporioides strains versus soil with just Orobanche and tomato. It was desired to ascertain whether the added genes would have an effect on the previously shown threshold levels for inoculum (2). Therefore, in the first experiment, sub-threshold levels of inoculum were used. In the second experiment, the inoculum levels were nearer the previously shown threshold. The untransformed fungi had no significant reduction in the number and size of Orobanche shoots at the sub-threshold inoculum levels used in both experiments (Fig. 4A and B). IAAoverproducing $F$. oxysporum and $F$. arthrosporioides strains at the same inoculum levels decreased the number of Orobanche shoots appearing compared with the wild type (Fig. 4A and B). The reduction in both number and size of the emerged Orobanche shoots indicated hypervirulence of some transgenic lines (Table 2). Single transformants (iaaM)F. oxysporum 62 and (iaaM)F. arthrosporioides 5 were significantly more active than wild-type $F$. oxysporum or F. arthrosporioides in reducing both the total number of shoots and the total number of shoots greater than $5 \mathrm{~cm}$ (Table 2). The single $($ iaaM $) F$. arthrosporioides transformant 5 was significantly more active than wild-type $F$. arthrosporioides in

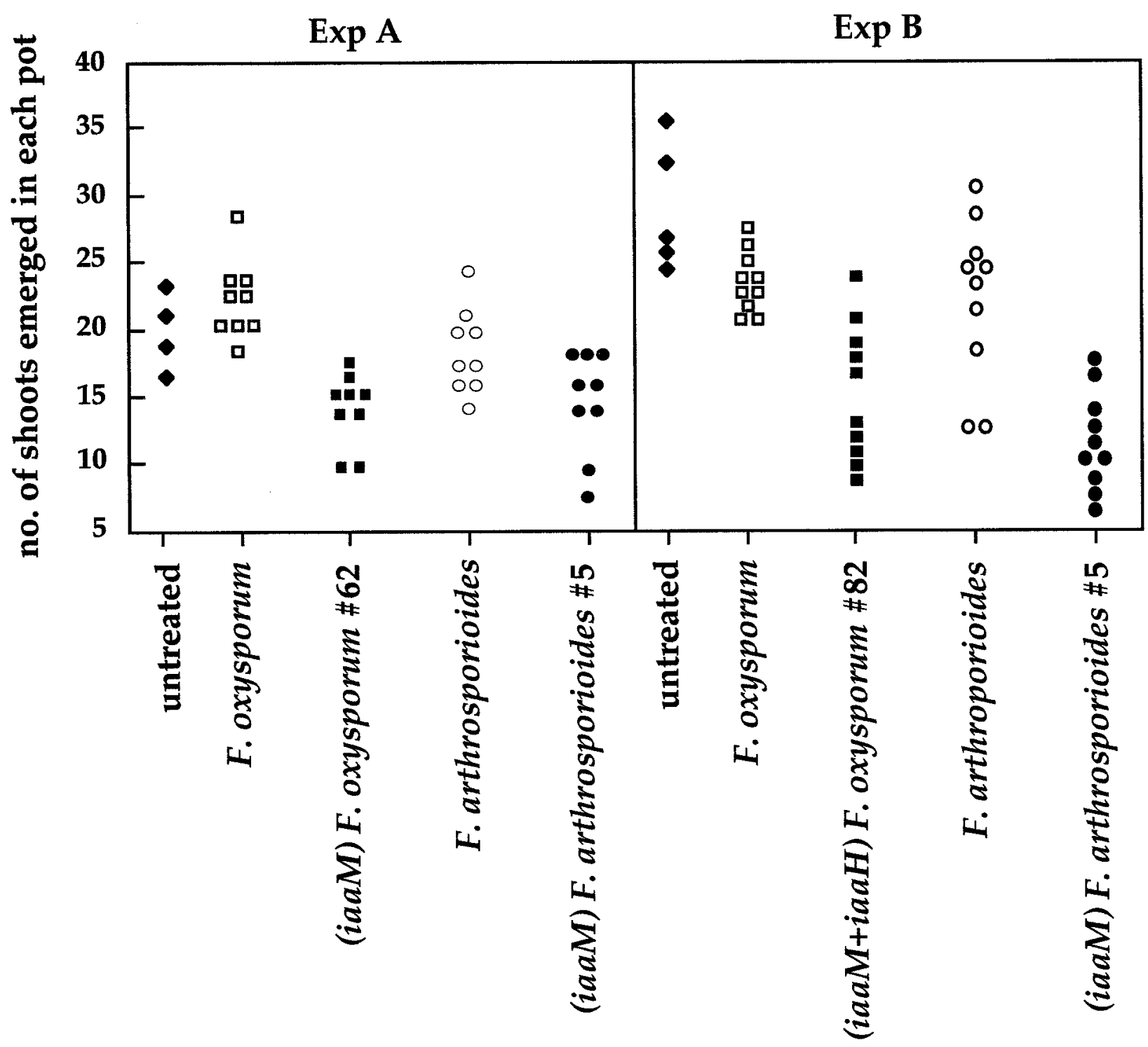

Fig. 4. Hypervirulence of transgenic Fusarium oxysporum and F. arthrosporioides. Each point represents the data from a single pot. 
reducing the total number of shoots, but not better in reducing the number of those shoots larger than $5 \mathrm{~cm}$ (Table 2). The higher inoculum level used in the second experiment may have allowed F. arthrosporioides 5 to exert a significant effect. Cotransformant $($ iaaM+iaaH)F. oxysporum 82 was significantly more active in reducing the number and size of shoots than the wild-type $F$. oxysporum and the single transformants (Table 2).

\section{DISCUSSION}

The presence of both the iaaM and iaaH genes cotransformed into the fungus is required for maximal IAA production and maximal suppression of Orobanche spp. The production of IAM contributed to the enhanced virulence of both (iaaM)F. oxysporum and $(i a a M) F$. arthrosporioides compared with the wild-type pathogen. Some (iaaM)F. oxysporum and (iaaM)F. arthrosporioides transformants were more effective IAA producers than the wild type. Possible explanations for the increased IAA levels found in the culture filtrates of some transformants bearing only the iaaM gene might be due to auto-oxidation of IAM to IAA (12), or that this pathway may exist in these species as previously shown for Colletotrichum gloeosporioides (27). Wild-type F. oxysporum did not accumulate IAM, but strains of (iaaM)F. oxysporum accumulated IAM (Fig. 3A). F. oxysporum strains cotransformed with both iaaM and iaaH accumulated up to 12 times more IAA than the wild type, because they could enzymatically convert the overproduced IAM into IAA (Fig. 3B; Table 1). Strains of $($ iaaM)F. arthrosporioides and wild-type $F$. arthrosporioides all produced some IAA and IAM (Fig. 3C). Many of the (iaaM)F. arthrosporioides strains accumulated an unidentified indole $\left(R_{f}=0.63\right)$ that was not found in wild-type $F$. arthrosporioides culture filtrates (Fig. 3C). It cannot be disregarded that the unidentified indole produced by $($ iaaM)F . arthrosporioides strains might play a role in the increased virulence of (iaaM)F. arthrosporioides 5 because wild-type $F$. arthrosporioides endogenously produces some IAA and IAM.

Viable colonies of $F$. arthrosporioides cotransformed with both $i a a M$ and $i a a H$ genes have not been obtained despite repeated attempts. If selectable markers could be found for (iaaM)F. arthrosporioides and (iaaH)F. arthrosporioides, then it might be possible to form (iaaM+iaaH)F. arthrosporioides heterokaryons. It is equally reasonable to assume that cotransformation could be made. Perhaps there is a lethal antagonism between the genes in this particular species. There may be a seeming contradiction between the in vitro results showing that IAA production is enhanced more when tryptophan is in the medium and the hypervirulence experiments where no exogenous tryptophan was added. Tryptophan may be naturally supplied to the Fusarium spp. from

TABLE 2. Suppression of emergence and of size of Orobanche shoots by transgenic Fusarium oxysporum and $F$. arthrosporioides overproducing indole-3-acetic acid (IAA) ${ }^{\mathrm{a}}$

\begin{tabular}{lcccc}
\hline Treatment & Strain & Genes & $\begin{array}{c}\text { Total no. } \\
\text { of shoots }\end{array}$ & $\begin{array}{c}\text { Shoots } \\
>50 \mathrm{~mm}\end{array}$ \\
\hline Experiment A & & & & \\
F. oxysporum & Wild type & $\ldots$ & 21.7 & 8.2 \\
F. oxysporum & 62 & iaaM & $13.6^{* *}$ & $5^{*}$ \\
F. arthrosporioides & Wild type & $\ldots$ & 19.4 & 5.8 \\
F. arthrosporioides & 5 & iaaM & $14.4^{*}$ & 4.6 \\
Experiment B & & & & \\
F. oxysporum & Wild type & $\ldots$ & 23.6 & 15.6 \\
F. oxysporum & 82 & iaaM+iaaH & $15.4^{* *}$ & $8.9^{* *}$ \\
F. arthrosporioides & Wild type & $\ldots$ & 22.7 & 14.3 \\
F. arthrosporioides & 5 & iaaM & $12^{* *}$ & $7.1^{* *}$ \\
\hline
\end{tabular}

${ }^{a}$ Because there were no significant differences among the results from the different inoculum levels, the data were averaged. * and ** indicate significant differences at $P<0.01$ or 0.05 , respectively, as determined by Student's paired $t$ test. Mock-inoculated wild type was used. root exudates of the tomato plants attacked by Orobanche. Tomato excretes numerous amino acids (14) and tryptophan was detected in tomato root sap (28).

There have been many publications containing reports that IAA is necessary for pathogenicity $(20,31)$, but none showing that transgenically enhanced IAA production leads to enhanced virulence. The results in this report indicate that transgenic $F$. oxysporum and $F$. arthrosporioides overproducing IAA have enhanced virulence, which results in a decrease in the number and size of Orobanche shoots (Table 2). The suppression of both the number and size of the shoots implies that the hypervirulent fungi prevent or delay Orobanche attachment to tomato or severely inhibit Orobanche growth. The best result would be no Orobanche. Still, tomato with delayed Orobanche attachment will suffer considerably less damage than plants with early attachments. Early attachment translates to a greater impact on crop yield. Neither the wild type (2) nor the hypervirulent fungi appeared to negatively affect the normal growth of the tomato plants (6), however the tomato plants treated with $F$. oxysporum or $F$. arthrosporioides were more vigorous, taller, and had larger fruit compared with those plants grown in mock-inoculated soil (6). Indeed, the transgenic lines of both Fusarium spp. colonize tomato roots, growing along them for great distances in the soil, as followed by gus or gfp in tandem with the other F. oxysporum and $F$. arthrosporioides transformants $(3,6)$.

The potential release of hypervirulent fungi in the environment raises safety concerns from the persistence of the fungi in the environment and the possibility of transfer of hypervirulent transgenes from the biocontrol agent to a pathogen of a crop. Failsafe mechanisms have been proposed to prevent spread and mitigate introgression of transgenic hypervirulent biocontrol fungi (16). Asporogenic deletion mutants of the transgenic hypervirulent fungi would prevent the spread. Asporogenic mycelia could be formulated in 'Stabileze' that retained high infectivity after more than a year in cold storage $(1,3)$. Mitigating genes would be added in tandem with the hypervirulent genes to reduce fitness or precluding infection of crops (16). For example, antimelanizing genes would inhibit appressorium formation of crop pathogens (16). There were no appressoria formed during infection of Orobanche by the Fusarium spp. (6).

The results obtained from the hypervirulence studies may have implications for other systems that use mycoherbicides for weed control.

\section{ACKNOWLEDGMENTS}

This research was supported by a DGF trilateral Israel-GermanPalestinian project (awarded to J. Gressel) and by grant 525/95 of the Israel Academy of Sciences (awarded to A. Sharon). J. Gressel holds the Gilbert de Botton Chair of Plant Sciences.

\section{LITERATURE CITED}

1. Amsellem, Z., Barghouthi, S., Cohen, B., Goldwasser, Y., Gressel, J., Hornok, L., Kerenyi, Z., Kleifeld, Y., Kroschel, J., Sauerborn, J., MullerStover, D., Thomas, H., Vurro, M., and Zonno, M.-C. 2001. Recent advances in the biocontrol of Orobanche (broomrape species). Biocontrol 46:211-228.

2. Amsellem, Z., Kleifeld, Y., Kerenyi, Z., Hornok, L., Goldwasser, Y., and Gressel, J. 2001. Isolation, identification, and activity of mycoherbicidal pathogens from juvenile broomrape plants. Biol. Control 21:274-284.

3. Amsellem, Z., Zidack, N. K., Quimby, P. C., Jr., and Gressel, J. 1999. Long term dry preservation of active mycelia of two mycoherbicidal organisms. Crop Prot. 18:643-649.

4. Brandl, M., Clark, E. M., and Lindow, S. E. 1996. Characterization of the indole-3 acetic acid (IAA) biosynthetic pathway in an epiphytic strain of Erwinia herbicola and IAA production in vitro. Can. J. Microbiol. 42:586-592.

5. Brandl, M. T., and Lindow, S. E. 1998. Contribution of indole-3-acetic acid production to the epiphytic fitness of Erwinia herbicola. Appl. Environ. Microbiol. 64:3256-3263. 
6. Cohen, B. 2001. Ontogeny of pathogenesis and the biochemical responses of Orobanche following infection by compatible Fusarium spp. $\mathrm{Ph} . \mathrm{D}$. thesis. Weizmann Institute of Science, Rehovot, Israel.

7. Comai, L., and Kosuge, T. 1982. Cloning and characterization of iaaM, a virulence determinant of Pseudomonas savastanoi. J. Bacteriol. 149:40-46.

8. Daboussi, M. J., Djeballi, A., Gerlinger, C., Blaiseau, P. L., Bouvier, I., Cassan, M., Lebrun, M. H., Parisot, D., and Brygoo, Y. 1989. Transformation of seven species of filamentous fungi using the nitrate reductase gene of Aspergillus nidulans. Curr. Genet. 15:453-456.

9. Deshpande, S., and Hall, J. C. 2000. Auxinic herbicide resistance may be modulated at the auxin-binding site in wild mustard (Sinapis arvensis L.): A light scattering study. Pestic. Biochem. Physiol. 66:41-48.

10. Ehmann, A. 1977. The van Urk-Salkowski reagent-A sensitive and specific chromogenic reagent for silica gel thin-layer chromatographic detection and identification of indole derivatives. J. Chromatogr. 132: 267-276.

11. Ek, M., Lyungquist, P. O., and Stenström, E. 1983. Indole-3-acetic acid production by mycorrhizal fungi determined by gas chromatographymass spectrometry. New Phytol. 94:401-407.

12. Ernstsen, A., Sandberg, G., and Crozier, A. 1986. Effects of sodium diethyldithiocarbamate, solvent, temperature and plant extracts on the stability of indoles. Physiol. Plant 68:519-522.

13. Fry, S. C. 1989. Cellulases, hemicellulases and auxin-stimulated growth: A possible relationship. Physiol. Plant 75:532-536.

14. Gamliel, A., and Katan, J. 1992. Influence of seed and root exudates on fluorescent pseudomonads and fungi in solarized soil. Phytopathology 82:320-327.

15. Gaudin, V., Vrain, T., and Jouanin, L. 1994. Bacterial genes modifying hormonal balances in plants. Plant Physiol. Biochem. 32:11-29.

16. Gressel, J. 2001. Potential failsafe mechanisms against spread and introgression of transgenic hypervirulent biocontrol fungi. Trends Biotechnol. 19:149-154.

17. Gruen, H. E. 1959. Auxins and fungi. Annu. Rev. Plant Physiol. 10:405440 .

18. Kawaguchi, M., Fujioka, S., Sakurai, A., Yamaki, Y. T., and Syono, K. 1993. Presence of a pathway for the biosynthesis of auxin via indole-3acetamide in trifoliata orange. Plant Cell Physiol. 34:121-128.

19. Kawaguchi, M., Kobayashi, M., Sakurai, A., and Syono, K. 1991. The presence of an enzyme that converts indole-3-acetamide into IAA in wild and cultivated rice. Plant Cell Physiol. 32:143-149.

20. Kosuge, T., and Sanger, M. 1986. Chapter six: Indoleacetic acid, its synthesis and regulation: A basis for tumorigenicity in plant disease. Pages 147-161 in: The Shikimic Acid Pathway, Recent Advances in Phytochemistry. E. E. Conn, ed. Plenum Press, New York.

21. Magie, A. R., Wilson, E. E., and Kosuge, T. 1963. Indole acetamide as an intermediate in the synthesis of indoleacetic acid in Pseudomonas savastanoi. Science 141:1281-1282.

22. Manulis, S., Valinski, L., Gafni, Y., and Hershenhorn, J. 1991. Indole-3acetic acid biosynthetic pathways in Erwinia herbicola in relation to pathogenicity on Gypsophila paniculata. Physiol. Mol. Plant Pathol.
39:161-171.

23. Parker, C., and Riches, C. R. 1993. Parasitic Weeds of the World: Biology and Control. CAB International, Wallingford, UK.

24. Punt, P. J., Oliver, R. P., Digemans, M. A., Pouwels, P. H., and Van den Hondel, C. A. M. J. J. 1987. Transformation of Aspergillis based on the hygromycin B resistance marker from Escherichia coli. Gene 56:117124.

25. Rajagopal, R., Tsurusaki, K., Kannangara, G., Kuraishi, S., and Sakurai, N. 1994. Natural occurrence of indoleacetamide and amidohydrolase activity in etiolated aseptically-grown squash seedlings. Plant Cell Physiol. 35:329-339.

26. Robinette, D., and Matthysse, A. G. 1990. Inhibition by Agrobacterium tumefaciens and Pseudomonas savastanoi of development of the hypersensitive response elicited by Pseudomonas syringae pv. phaseolicola. J. Bacteriol. 172:5742-5749.

27. Robinson, M., Riov, J., and Sharon, A. 1998. Indole-3-acetic acid biosynthesis in Colletotrichum gloeosporioides f. sp. aeschynomene. Appl. Environ. Microbiol. 64:5030-5032.

28. Rybicka, H. 1981. Tryptophan in root exudate of mock orange and tomato. Acta Physiol. Plant 3:95-98.

29. Saotome, M., Shirahata, K., Nishimura, R., Yahaba, M., Kawaguchi, M., Syono, K., Kitsuwa, T., Ishii, Y., and Nakamura, T. 1993. The identification of indole-3-acetic-acid and indole-3-acetamide in the hypocotyls of Japanese cherry. Plant Cell Physiol. 34:157-159.

30. Shinshi, H., Mohnen, D., and Meins, F. J. 1987. Regulation of a plant pathogenesis-related enzyme: Inhibition of chitinase mRNA accumulation in cultured tobacco tissues by auxin and cytokinin. Proc. Natl. Acad. Sci. USA 84:89-93.

31. Smidt, M., and Kosuge, T. 1978. The role of indole-3-acetic acid accumulation by alpha methyl tryptophan resistant mutants of Pseudomonas savastonoi in gall formation on oleanders. Physiol. Plant Pathol. 13:203-214.

32. Srivastava, B. I. S. 1964. Investigations of the occurrence and biosynthesis of indolepyruvic acid in plant tissues and bacteria. Plant Physiol. 39:781-785.

33. Taguchi, T., Uraguchi, A., and Katsumi, M. 1999. Auxin- and acidinduced changes in the mechanical properties of the cell wall. Plant Cell Physiol. 40:743-749.

34. Tudzynski, B., and Sharon, A. 2001. Biosynthesis, biological role and application of fungal phytohormones. Pages 183-211 in: The MycotaIndustrial Applications. H. D. Osiewacz, ed. Springer-Verlag, Berlin.

35. Turgeon, B. G., Garber, R. C., and Yoder, O. C. 1987. Development of a fungal transformation system based on selection of sequences with promoter activity. Mol. Cell Biol. 7:3297-3305.

36. Vanderhoef, L. N., and Dute, R. R. 1981. Auxin-related wall loosening and sustained growth in elongation. Plant Physiol. 67:146-149.

37. Yamada, T., Palm, C. J., Brooks, B. T. K., and Kosuge, T. 1985. Nucleotide sequences of the Pseudomonas savastanoi indoleacetic acid genes show homology with Agrobacterium tumefaciens T-DNA. Proc. Natl. Acad. Sci. USA 82:6522-6526. 